\title{
DEMOGRAPHIC CONSEQUENCES OF AN ONTOGENETIC SHIFT BY A SEA URCHIN IN RESPONSE TO HOST PLANT CHEMISTRY
}

\author{
Jane E. Williamson, ${ }^{1}$ David G. Carson, Rocky de Nys ${ }^{2}$ and Peter D. Steinberg
}

School of Biological, Earth and Environmental Sciences, and Centre for Marine Biofouling and Bio-Innovation, University of New South Wales, Sydney, New South Wales 2052 Australia

\begin{abstract}
Habitat selection that maximizes both larval settlement success and subsequent juvenile and adult performance is a fundamental challenge for marine benthic organisms with complex life histories (e.g., planktonic larvae). For benthic herbivores, chemical cues from macroalgae can strongly influence both larval settlement/metamorphosis and subsequent performance. We compared the effects of chemical cues from host algae on different life history stages of the "arboreal" sea urchin Holopneustes purpurascens. In sublittoral habitats near Sydney, Australia, H. purpurascens occurred primarily on two algal hosts: red alga (Delisea pulchra) and kelp (Ecklonia radiata). Urchins on E. radiata were significantly larger than those on $D$. pulchra, but no recruits occurred on E. radiata. In experiments, larvae rapidly metamorphosed in the presence of $D$. pulchra, but metamorphosis was delayed or nonexistent in the presence of E. radiata. D. pulchra produces a polar chemical inducer of metamorphosis not found in E. radiata. In contrast to larval metamorphosis, feeding and performance of juvenile and adult urchins were considerably worse on $D$. pulchra than on E. radiata. Feeding experiments confirmed that nonpolar metabolites (halogenated furanones) in D. pulchra deter feeding. Adding natural concentrations of the most abundant furanone to otherwise palatable diets completely inhibited feeding. Urchins fed $D$. pulchra had reduced survival, growth, and reproduction compared to those fed $E$. radiata. $H$. purpurascens did not thrive on the alga on which they preferentially settled; therefore, postrecruitment movement from $D$. pulchra to E. radiata was crucial to fitness. Urchins in D. pulchra beds moved between plants at night and preferred E. radiata in habitat preference experiments. Movement was constrained by diurnal predators, particularly damselfish Parma microlepis. When $H$. purpurascens was removed from their algal hosts during the day (but not at night), P. microlepis "clipped" their spines and tube feet. Removal of $10 \%$ of an urchin's spines and tube feet was fatal. $H$. purpurascens recruits onto a host that does not support persistence of the benthic phase and then shifts host plants, incurring a predation risk. Though chemically mediated, ontogenetic shifts in host plant use are known for insect herbivores, this is the first known example in a marine herbivore.
\end{abstract}

Key words: Australia; Delisea pulchra; Ecklonia radiata; habitat preference; herbivory; Holopneustes purpurascens; life history; macroalgae; mesograzers; plant-herbivore interactions; secondary metabolites.

\section{INTRODUCTION}

Many animals have complex life cycles (Werner 1988), involving an abrupt ontogenetic change in the organism's morphology, physiology, and behavior. This usually occurs during the transition from the larval to the juvenile or adult stages of the organism and is often associated with a complete change in habitat or mode of feeding (Mayhew 2001). Classic examples of animals with complex life cycles include amphibians, holometabolous insects, and many marine invertebrates

Manuscript received 25 September 2002; revised 22 August 2003; accepted 23 August 2003. Corresponding Editor: S. G. Morgan.

${ }^{1}$ Present address: Department of Biological Sciences, Macquarie University, Sydney, New South Wales, 2109, Australia. E-mail: jwilliamson@ bio.mq.edu.au

${ }^{2}$ Present address: School of Marine Biology and Aquaculture, James Cook University, Townsville, Queensland, 4811, Australia. that change from planktonic larvae to benthic adults (Pawlik 1992, Thompson 1995, Hentschel 1999). This latter group includes many of the most important taxa of marine herbivores, such as echinoids and gastropods.

An important consequence of complex life histories to herbivores is that the dispersal phase of the life history that is broadly responsible for choosing a habitat or a host plant (e.g., ovipositing butterfly or planktonic larvae) is often not the stage that utilizes the habitat or plant (e.g., caterpillar or sea urchin). Thus there is the potential for traits of host plants to act differently or independently against different life history phases. Such traits include the chemical makeup of plants, which is a major factor affecting the behavior, ecology, and evolution of herbivores (Bernays and Chapman 1994, Arrontes 1999, Paul et al. 2001). Plant metabolites can affect anything from the initial colonization of host plants (or of habitats where the plants occur) to consumption and digestion of plants by her- 
bivores but may not act equally on larvae and adults (Courtney and Kibota 1990). Differential effects of plant metabolites on different life history stages of herbivores could have important consequences; e.g., failure by the dispersal stage to recognize metabolites acting against feeding or digestion by the benthic stage may be disastrous for animals with limited mobility.

Such differences in the effects of host plant metabolites against different life history stages can fundamentally affect host plant use by insect herbivores (Bernays and Chapman 1994, Thompson 1995, Mayhew 2001). However, although both marine invertebrate larvae and their corresponding benthic juveniles or adults are also strongly affected by host-derived chemical signals (Hay and Steinberg 1992, Pawlik 1992, Paul et al. 2001), the effects of host plant chemistry in mediating ontogenetic shifts in habitat and/or diet use for marine herbivores are largely unknown.

We investigated the effects of algal metabolites on the planktonic (larval) and benthic stages of the echinoid Holopneustes purpurascens (Temnopleuridae: Echinodermata) and the consequences to its demography. $H$. purpurascens, which occurs in shallow subtidal areas in temperate southeastern Australia, is a relatively unusual echinoid. Although comparable in size (e.g., up to $65 \mathrm{~mm}$ in test diameter) to other sea urchins that live on the sea floor and forage between individual plants, $H$. purpurascens lives enmeshed in the canopy of the algae that it consumes, using it as habitat as well as food (Steinberg 1995). Thus it exhibits characteristics of both mesograzers (sensu Brawley 1992) and more typical benthic herbivorous echinoids. At Bare Island, Sydney, H. purpurascens occurs predominantly in the fronds of the red foliose alga $D e$ lisea pulchra (Bonnemaisoniales: Rhodophyta) and in the laminae of the brown alga Ecklonia radiata (Laminariales: Phaeophyta) (Williamson et al. 2000). While abundances of $H$. purpurascens on the two hosts were similar, urchins from $D$. pulchra were, on average, significantly smaller than those from $E$. radiata (Williamson et al. 2000), and no urchins in the smallest size class (recent recruits) were found on E. radiata. Larval settlement and metamorphosis was rapidly induced by D. pulchra, but not E. radiata, due to a polar cue exuded from D. pulchra (Williamson et al. 2000). These observations, combined with the knowledge that both plants are rich in biologically active natural products (Delisea pulchra contains nonpolar halogenated furanones [de Nys et al. 1992, 1993] and Ecklonia radiata the brown algal polyphenolics known as phlorotannins [Ragan and Glombitza 1986]) led to the hypothesis that differential responses to algal metabolites by different life history phases was driving patterns of host-plant use by this echinoid.

To test this hypothesis, the following questions were investigated: (1) What are the size distributions of Holopneustes purpurascens on host plants around Sydney, and are distributions persistent over time? (2) Do larvae preferentially recruit among different host plants and does preference change with larval age? (3) What are the consequences for the benthic phase of larval metamorphosis on a particular host plant in terms of consumption, survival, growth, and reproduction? (4) Are adult $H$. purpurascens able to move between host plants, and do they show a preferences among hosts? (5) Does predation constrain postrecruitment movement between host plants?

\section{Methods \\ Study site}

This study was done primarily in sublittoral habitats

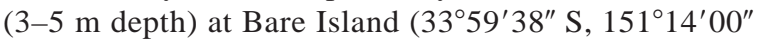
$\mathrm{E})$, near Sydney, Australia. Bare Island is typical of shallow subtidal areas in temperate southeastern Australia (Underwood et al. 1991), comprised of mosaics of algal dominated habitats and "barrens" (areas largely lacking foliose algae). Beds of Delisea pulchra (Greville) Montagne and forests of Ecklonia radiata (Turn.) J. Agardh. are common at this site, with typically disjunct distributions. Subcanopies of the crustose coralline (red) algae Corallina officinalis and Amphiroa anceps are common under both D. pulchra and E. radiata. Other macroalgae (e.g., Sargassum linearifolium, various Dictyotales) occur interspersed among these species. Three other similar sites within the Sydney region, Long Bay, Shark Bay, and Cape Banks, were also studied.

\section{Temporal abundance and size distribution of urchins}

The abundance and size distribution of Holopneustes purpurascens on host algae was estimated using nondestructive sampling methods. To see if this biased our ability to detect smaller urchins, a pilot study comparing nondestructive and destructive sampling was done. Ten $0.25-\mathrm{m}^{2}$ quadrats were randomly placed in a $5 \times 5 \mathrm{~m}^{2}$ grid that included both an Ecklonia radiata forest and a Delisea pulchra bed. All $H$. purpurascens in each quadrat were counted and measured (oral-aboral diameter $\pm 1 \mathrm{~mm}$ ) in situ and then all algae and organisms (including $H$. purpurascens) in each quadrat collected. Samples were thoroughly searched again in the laboratory and the number of urchins sampled using each method compared using a paired $t$ test. Size distributions were compared using a Kolmogorov-Smirnov $G$ test for continuous data (Sokal and Rohlf 1995). Neither abundances (paired $t$ test: $t(D$. pulchra and $E$. radiata $)=0.343$ ), nor size distributions (KolmogorovSmirnov $G$ test: $E$. radiata, $n=43, P=0.384 ; D$. pulchra, $n=30, P=0.999)$ between nondestructive and destructive methods differed, and nondestructive sampling was used subsequently.

The abundance of Holopneustes purpurascens was measured at Bare Island in each of two 10- $\mathrm{m}^{2}$ sites positioned within beds of each of the two main host plants, Delisea pulchra and Ecklonia radiata, and 
where these two habitats met (the "boundary"). A grid was placed in each site, five $1-\mathrm{m}^{2}$ quadrats positioned, and the number of urchins per plant counted for all plants in each quadrat. This was done during March (autumn) and September (spring) in 1996, with different $10-\mathrm{m}^{2}$ sites surveyed in each habitat for each time. Since the difference in sites precluded any formal analysis of temporal effects, abundance in each habitat was analyzed by separate two-factor nested analyses of variances (ANOVA; site nested within habitat) for each time.

Size distributions of Holopneustes purpurascens on Delisea pulchra and Ecklonia radiata were assessed separately during March and September 1996 by measuring the size of all urchins on individual plants in 1$\mathrm{m}^{2}$ quadrats described previously. The size of urchins between the two habitats was compared using a twofactor ANOVA, with time and habitat fixed (see Methods: Statistical analysis).

At Bare Island there were two visually distinct types of Ecklonia radiata forests: those "bordered" by beds of Delisea pulchra and those "isolated" from these beds. Isolated forests were either entirely surrounded by deforested areas lacking foliose macroalgae, or bordered by vertical walls or deep crevices that were also largely devoid of macroalgae. To determine if the density and size of Holopneustes purpurascens in E. radiata forests were related to their proximity to $D$. pulchra beds, abundance and size of urchins in both bordered and isolated $E$. radiata forests was measured in 10 randomly placed $0.25-\mathrm{m}^{2}$ quadrats placed in each of six bordered and six isolated forests, all picked haphazardly. Size distribution was assessed as above in three each of the bordered and isolated forests. Both the abundance and size distributions of $H$. purpurascens in isolated vs. bordered forests were compared by ANOVA.

Host plant use by Holopneustes purpurascens was assessed more broadly around Sydney in February (summer) 2001 by surveys at four locations: Shark Bay, Long Bay, Cape Banks, and Bare Island. At each location, ten $1-\mathrm{m}^{2}$ quadrats were haphazardly placed in habitats containing macroalgae that were typical of the location, and the number of each algal species, the number of urchins on each plant, and the size of each urchin recorded within each quadrat. Both abundance and size of $H$. purpurascens on each host were compared between locations using one-factor ANOVAs.

\section{Larval response to host plants}

Larval Holopneustes purpurascens readily settle and metamorphose in response to a low molecular mass water-soluble compound exuded from Delisea pulchra (Williamson et al. 2000). Larvae also settle and metamorphose when exposed to other red algae (but not green or brown algae), but this response is much lower and more varied (Williamson et al. 2000). H. purpurascens were found at some locations such as Shark Bay, however, where no D. pulchra was observed. One explanation for this observation is that if competent larvae are unable to detect the settlement cue for a protracted period of time, some larvae may metamorphose in the absence of the cue.

To test this idea, in March 2001 gametes from several male and female urchins from Bare Island were fertilized and competent larvae were reared as in Williamson et al. (2000). After six days postfertilization, one competent larva was added to a glass petri dish $(45 \mathrm{~mm}$ diameter) with $\sim 15 \mathrm{mg}$ (wet mass) of either Delisea pulchra, Ecklonia radiata, Amphiroa anceps, Corallina officinalis, or Sargassum linearifolium ( $n=20$ replicate dishes per algal species) in $5 \mathrm{~mL}$ of sterile filtered seawater. The latter three algae were chosen because they co-occur with the two main host plants. Controls of sterile filtered seawater alone (20 replicates) were included to measure metamorphosis in the absence of exogenous chemical cues. The percentage of metamorphosed larvae after 24 hours for each treatment was calculated and differences among treatments analyzed using a chi-square goodness-of-fit test (Sokal and Rohlf 1995). This experiment was repeated 18 days postfertilization with larvae from the same batch, but using different individuals.

\section{Feeding rates of benthic urchins on different host plants}

The feeding rates of adult Holopneustes purpurascens, 20-45 mm diameter, (urchins of this size are typically reproductively mature; Williamson and Steinberg 2002) on Delisea pulchra and Ecklonia radiata were determined in a no-choice feeding assay over 24 hours. No-choice assays were deemed appropriate for this urchin because of the tight coupling between habitat and diet (e.g., most urchins are unlikely to be faced with a simultaneous choice of host plants). Urchins were collected from Bare Island, measured, and placed in individual mesh chambers $(130 \times 200 \mathrm{~mm})$ to eliminate possible effects of density-dependent interactions on feeding (Peterson and Renaud 1989). The chambers were placed in replicate 40-L tanks (six chambers per tank) illuminated from above by Gro-lux fluorescent bulbs (Aquatics online, 6/3 Newlands Avenue, Bridgend, UK; $\left.9.4 \mu \mathrm{mol} \cdot \mathrm{m}^{-2} \cdot \mathrm{s}^{-1}\right)$ set at ambient photoperiod. The tanks comprised part of a 30,000-L recirculating seawater system that was maintained at a salinity of $34-36 \%$ and at field temperatures $\left(18-22^{\circ} \mathrm{C}\right)$. Treatments were randomly allocated among individual chambers and urchins sorted by size into treatments so that the sizes of urchins among treatments did not differ (ANOVA).

At the start of the experiment, $5 \mathrm{~g}$ (wet mass) of either Delisea pulchra or Ecklonia radiata was added to each chamber ( $n=20$ urchins per treatment). Additional treatments consisting of pieces of $D$. pulchra or E. radiata in separate tanks without urchins were included to control for autogenic change in mass not 
due to herbivory. All algal pieces were removed, reweighed, and tissue loss calculated after 24 hours. Differences in the rate of feeding between treatments were analyzed using a two-factor ANOVA, with algal species and the presence or absence of urchins as fixed factors, followed by an a posteriori comparison ( $\mathrm{Tu}-$ key's test) with the consumption means corrected for autogenic changes. The error mean square estimate from the original two-factor ANOVA was used in the Tukey's test (Peterson and Renaud 1989).

Holopneustes purpurascens barely consumed Delisea pulchra in this no-choice feeding experiment (see Results). Since $D$. pulchra contains biologically active halogenated furanones (de Nys et al. 1996), further nochoice feeding experiments were done to determine the effect of the crude nonpolar extract of D. pulchra, and then a purified furanone, on feeding by $H$. purpurascens. The nonpolar crude extract was prepared from $D$. pulchra freshly collected from Bare Island. The alga was blotted dry, exhaustively extracted in methanol, and reduced in vacuo at $50^{\circ} \mathrm{C}$ prior to partitioning between water and dichloromethane (DCM) to separate the polar and nonpolar fractions. After partitioning, the DCM-soluble (nonpolar) fraction (crude extract) was reduced in vacuo to dryness. The major secondary metabolite of D. pulchra, or "furanone 3" (1'R,5Z)-3-(1'-acetoxybutyl)-4-bromo-5-(bromomethylene) furan-2 $(5 H)$-one, was isolated from the crude extract following de Nys et al. (1993).

These urchins would not consume disks of agar, or other standard matrices used in these types of feeding assays (e.g., carrageen), but would consume agar when it was thinly coated onto laminae of Ecklonia radiata. Therefore extracts and metabolites were tested by offering the urchins treatments consisting of E. radiata, $E$. radiata thinly coated with agar, or E. radiata thinly coated with agar into which either extract or furanones had been incorporated. To prepare the agar coating, agar (Research Organics, Cleveland, Ohio, USA) was added to MilliQ water at $4 \%$ mass per volume, boiled until it had dissolved, and cooled to $50-60^{\circ} \mathrm{C}$. Crude extract was then incorporated into the agar so as to achieve a final concentration in the diet of $1 \%$ (an average concentration in D. pulchra; de Nys et al. 1996) of the combined dry mass of the agar and the E. radiata laminae (estimated from a previously established wet mass : dry mass relationship for this kelp). This method of establishing a concentration of extract in the diet was deemed most appropriate for Holopneustes purpurascens, which bites through kelp laminae. Furanone 3 was added to give a final concentration of $0.1 \%$ dry mass (Wright et al. 2000). Laminae of E. radiata ( $\sim 4$ $\mathrm{g}$ wet mass) were then coated in the agar-plus-crude or agar-plus-furanone solution. Other treatments $(n=15$ replicates per treatment) in these experiments included (1) laminae of $E$. radiata coated in the agar solution only (without the crude extract), and (2) E. radiata with no coating. Each experiment lasted for 24 hours. Con- trols for autogenic mass loss and analyses were done as described above for the algal feeding assay.

\section{Performance of benthic urchins on different host plants}

Holopneustes purpurascens metamorphosed rapidly in the presence of Delisea pulchra and (more slowly) in response to several other local red algae (Williamson et al. 2000), but not in response to Ecklonia radiata. To see if the performance of juveniles raised on different algae mirrored the effect of these algae on larval metamorphosis, survival and growth of newly metamorphosed juveniles on several monospecific algal diets was measured for three months.

Larvae were reared in the laboratory as described previously and metamorphosed in bulk (using Delisea pulchra) prior to the experiment. Three days after metamorphosis these individuals were transferred to a $2-\mathrm{L}$ glass beaker containing sterile filtered seawater and observed (microscopically) for four days to ensure that they were healthy. Urchins were not fed during this time. At the start of the experiment, the length and height of individual urchins were measured and they were put into small mesh cages $(45 \mathrm{~mm}$ diameter $\times$ $80 \mathrm{~mm}$ length; $2 \mathrm{~mm}$ mesh size; $n=10$ urchins per treatment $)$ within a large mesocosm $(0.6 \times 0.8 \times 1.2$ $\mathrm{m})$ plumbed into the recirculating seawater system previously described. Urchins were fed ad libitum on monospecific diets of Ecklonia radiata, D. pulchra, Amphiroa anceps, or Corallina officinalis, or starved. Algae were replaced three times a week and survivorship measured weekly. At the end of three months each urchin was remeasured and the proportional change from its initial volume as an ovoid (Williamson 2001) was calculated. Differences in growth among treatments were analyzed by one-factor ANOVA followed by Tukey's post hoc analyses. Differences in survivorship were analyzed by a chi-square goodness-of-fit test.

Although small Holopneustes purpurascens are found almost entirely on Delisea pulchra and large urchins on Ecklonia radiata, medium-sized urchins (30-45 mm test diameter) occur on both host plants. Thus in order to compare performance of the size range most likely to experience both host plants, a second laboratory growth experiment was done for three months with medium-sized urchins fed ad libitum either D. pulchra or E. radiata, or starved ( $n=20$ urchins per treatment). Algae were again replaced three times a week and survivorship measured at the end of each week. Growth was analyzed each month as the proportional change in initial volume (after $\ln (x+1)$ transformation) using one-factor ANOVAs followed by Tukey's post hoc analyses. At the end of three months differences in survivorship were analyzed via a chisquare goodness-of-fit test followed by more detailed pairwise comparisons using log-likelihood ratios ( $G$ tests; Sokal and Rohlf 1995). 
The reproductive status of these urchins was determined as a further measure of performance. At the end of the experiment each urchin was dissected, gonads separated out, and the gonads and the rest of the urchin dried separately at $60^{\circ} \mathrm{C}$ for a minimum of three days to a constant mass. After drying, gonad indices (GI) were calculated as (gonad dry mass/total dry mass) $\times$ $100 \%$. Data for both sexes were pooled as there is a significant correlation between the gonad index for male and female Holopneustes purpurascens (Williamson and Steinberg 2002). Raw data were arcsine transformed and differences in GI between treatments compared using a one-factor ANOVA followed by Tukey's tests.

\section{Preferences and movement of urchins between host plants}

The distribution and abundance data vs. the larval settlement preferences suggested that Holopneustes purpurascens may exhibit a general postrecruitment movement from Delisea pulchra to Ecklonia radiata. We were unable to mark and recapture these urchins nondestructively, and therefore long-term movement of urchins between the two host plants could not be directly observed. However, to test whether $H$. purpurascens exhibits directional movement between host plants when offered a choice, experiments on host preference were done in the laboratory and in the field. The laboratory experiment was done with urchins (20$45 \mathrm{~mm}$ diameter) collected from laminae of $E$. radiata one day prior to the experiment and kept in holding tanks with flowing seawater and fed $E$. radiata ad libitum. The experiment was done in 40-L tanks in the recirculating seawater system described previously. For each trial, one frond each of D. pulchra and one lamina of $E$. radiata were attached to the bottom of the tank with weights at their edges so that they were lying flat on the bottom and touching in the middle. The laminae of $E$. radiata was cut to ensure that roughly equal amounts of each algal species was present. At the start of each trial one urchin was placed in the center of the two algal species. Each trial ran until the urchin had moved either entirely onto one of the pieces of alga (and then scored as either " $D$. pulchra" or " $E$. radiata") or had moved off both pieces of algae (where it was scored as "no-choice"). This trial was repeated 30 times, with a new urchin and new algae for each trial. Data were analyzed with a chi-square test.

Preference of Holopneustes purpurascens between hosts in the field was examined in two algal transplant experiments. In the first experiment, 20 Ecklonia radiata plants were transplanted into a Delisea pulchra habitat, and $20 \mathrm{D}$. pulchra plants into an E. radiata habitat. All plants were checked to ensure that there were no $H$. purpurascens attached. To avoid bias due to plant size (the larger a plant the more likely it will be encountered), transplanted $E$. radiata were trimmed to sizes approximating that of $D$. pulchra (including removal of the stipe and holdfast). Transplanting methods differed between species due to the marked difference in thallus morphology. Small holes were punched into the intercalary meristem region of the trimmed E. radiata, and pieces of plastic tubing containing cable ties inserted so that the plants could be cable tied to the substratum without tearing. D. pulchra were transplanted by affixing their holdfasts with cable ties to the top of E. radiata that were removed of all laminae. To control for the effects of trimming and transplanting, 20 plants of each species that were devoid of urchins were transplanted into the same habitat they originated in, and 20 plants were tagged but otherwise left undisturbed in each habitat. E. radiata were transplanted back to their own habitat by cutting plant stipes and attaching the removed laminae to different stipes using cable ties. D. pulchra were transplanted back to their own habitat by cable-tying plant holdfasts to nails embedded in the substratum. All plants within each habitat were connected with fluorescent nylon line for ease of recovery. The experiment ran overnight and the number of urchins on each plant (transplants or controls) was recorded the following morning and compared using a two-factor ANOVA, with the factors species and transplant fixed.

The previous experiment kept the Ecklonia radiata laminae (the part of the plant inhabited by Holopneustes purpurascens) at the same height above the substratum as thalli of Delisea pulchra. E. radiata is a stipitate alga, however, with laminae raised above the substratum by $\sim 20-30 \mathrm{~cm}$. Therefore, a second transplant experiment was done where entire $E$. radiata plants were transplanted into $D$. pulchra habitats to see if laminae elevated by a stipe prevented urchins from occupying the kelp (this also controlled for the possible effects of cutting $E$. radiata down to size in the previous experiment). Entire plants were attached to the substratum by cable tying their holdfasts to dynabolts (Ramset Fasteners Australia, Sydney, Australia) fixed to the substratum. The controls were the same as for the previous experiment. This experiment was also left overnight and numbers of $H$. purpurascens on both host plants recorded and compared by one-factor ANOVA.

If Holopneustes purpurascens move from Delisea pulchra to Ecklonia radiata, it should be possible to observe some urchins in transit (on the substratum). Therefore, diel observations of urchins on host plant habitats were done in five fixed $0.25-\mathrm{m}^{2}$ quadrats in each of three fixed sites. Quadrat locations in each habitat were fixed by attaching buoyant rope markers to the substratum using Ramset dynabolts. The position of $H$. purpurascens in D. pulchra beds was recorded as one of two categories: on plants of D. pulchra or coralline turf (i.e., the predominant primary cover of the substratum). In E. radiata beds, position was recorded as either on plants of E. radiata or on the substratum (as coralline turf was lacking). Sampling was done immediately after sunrise, shortly before sunset, 
then immediately after sunrise again to capture $\sim$ a 12 hour day/12 hour night pattern. Data were analyzed using a $G$ test on the two-way (time $\times$ position) $\log$ linear model.

\section{Predation of urchins on host plants}

Since movement of sea urchins is often constrained by predation (Scheibling 1996), we investigated if predation could constrain movement of Holopneustes purpurascens between host plants. Assuming that the most likely predators were visually hunting fishes, the common damselfish Parma microlepis was a probable predator of $H$. purpurascens, regularly attacking the urchins when they were removed from their host plant. Given that $H$. purpurascens are exposed (uncovered) when on the substratum between host plants, they may be most vulnerable to predation by these fish when moving. Therefore, to see if predation occurred while urchins were mobile, diel patterns in predation of $H$. purpurascens by $P$. microlepis with differing amounts of shelter from their host plants were measured in the field. Exposed and covered (wrapped in Ecklonia radiata) $H$. purpurascens were placed on the substratum in areas where $P$. microlepis were present, and the number of bites that $P$. microlepis took from the urchins was then recorded over two minutes. This was done at two sites within each of three habitats: Delisea pulchra, E. radiata, and a barrens habitat, devoid of foliose macroalgae. Five pairs of exposed and covered urchins were observed in succession at each site, and the experiment was repeated four times; twice at night and twice during the day. Bite rates were compared using a four-factor ANOVA, with time, habitat, and algal coverage as fixed factors, and site nested within habitat.

Holopneustes purpurascens are typically found wrapped in the fronds of the alga it inhabits. Since most visually hunting fish attack during the day, we examined if the use of the host plant as shelter varied as a function of host species or time of the day. Fifteen fixed $0.25-\mathrm{m}^{2}$ quadrats were marked in both $D$. pulchra habitats and $E$. radiata forests as per the movement experiments, and the degree that algal fronds covered each urchin was measured within each quadrat. Three categories of algal "coverage" were used: 0-50\%, 51$90 \%$, and 91-100\%. Measurements of shelter were taken twice over 24 hours, once during the day and once during the night (12 hours apart). This was done on two dates 14 days apart, with the order of sampling reversed on the second date, i.e., sampling was done at night prior to day. Coverage was compared with a $G$ test on the three-way (time $\times$ habitat $\times$ coverage) log-linear model.

When Parma microlepis attacked an urchin it bit off pieces of tube feet and spines, leaving the test intact. Therefore, a further field experiment was done to estimate the area of spines and tube feet that these fish remove. During the day, five large $(>45 \mathrm{~mm})$ urchins were placed uncovered on the substratum near $P$. $m i$ - crolepis in a bed of Delisea pulchra where all other Holopneustes purpurascens had been removed. Since exposed urchins move immediately in daylight hours until they find available algal shelter, this experiment estimated the extent of damage done to an urchin moving between hosts in the presence of a predator. The urchins were collected from the host plant they had reached and the percentage loss of spines and tube feet estimated visually. This experiment was repeated three times and percentage loss analyzed via a one-factor ANOVA to compare differences in loss over the three times.

Damage by Parma microlepis to Holopneustes purpurascens was sublethal in the short term. Therefore an experiment was done to determine whether the "clipping" of tube feet and spines by these fish caused long-term effects on the urchins. Urchins were monitored in the laboratory over time after removal of $0 \%$, $10 \%$, or $50 \%$ of their spines and tube feet $(n=21$ urchins per treatment). Spines and tube feet were removed with scissors, and urchins in each treatment were placed into three $40-\mathrm{L}$ plastic tanks (seven urchins in each tank) in the recirculating seawater system and fed Ecklonia radiata. The tanks were monitored daily for 14 days, and any urchins that died during the experiment were removed. Differences in time until death between treatments were compared by two-factor ANOVA, with treatment (percentage loss) as a fixed factor and tank nested within percentage loss.

\section{Statistical analysis}

Details of most analyses are described previously. Prior to all ANOVAs, homogeneity of variance was tested. For balanced analyses, Cochran's test (Winer et al. 1991) was used. Where analyses were unbalanced, Cochran's test was done using degrees of freedom from treatments with the highest replication to ensure a conservative test. Where data were heavily skewed or bimodal, making Cochran's tests invalid, homoscedasticity was checked using frequency histograms of the residuals, plots of residuals vs. estimates, and normality distributions of the residuals. If the a priori assumptions for ANOVA were not met, appropriate transformations were made (stated in the Results). Means in the Results section are presented with \pm 1 SE. In nested ANOVAs, if $P>0.25$ for the nested factor, it was pooled (Sokal and Rohlf 1995).

For log-likelihood ratios ( $G$ tests), post hoc tests used were an adaptation of the unplanned $G$ test for homogeneity of replicates (Sokal and Rohlf 1995). This test is similar to multiple range tests used after ANOVA, and involves a trial and error method of analyzing different subgroups of treatments using a $G$ test. Treatments are ranked, then subgroups of these treatments are analyzed with a $G$ test. If the result is significant, the subgroup of treatments is heterogeneous. If more than one-fifth of the expected frequencies were less than five in the overall $G$ test, the contingency 


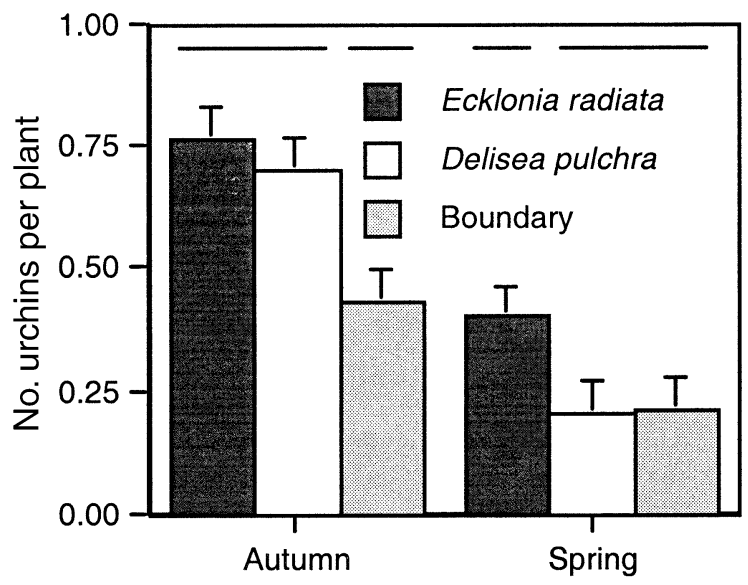

FIG. 1. Number (mean $+1 \mathrm{SE})$ of Holopneustes purpurascens per plant at Bare Island at two sampling times in Ecklonia radiata forests bordered by Delisea pulchra beds, D. pulchra beds, and the boundary between these two habitats. For each time, habitats sharing a horizontal line (at the top of the figure) do not differ significantly at $P=0.05$ (Tukey's hsd test).

analysis is rendered suspect (Zar 1984) so categories were pooled here where possible and significance levels taken at $P<0.01$ instead of 0.05 .

\section{RESULTS}

Temporal abundance and size distribution of urchins

The density of Holopneustes purpurascens at Bare Island in autumn did not differ between Ecklonia radiata and Delisea pulchra (one-factor ANOVA, $F_{2,27}$ $=6.412, P<0.01$; Fig. 1 ). However, significantly more urchins occurred on plants in these habitats than on plants in their shared boundary (Fig. 1). During spring, urchins were significantly more abundant in E. radiata forests than in the other two habitats (one-factor ANOVA, $F_{2,27}=6.184, P<0.01$; Fig. 1). Although densities of urchins appeared lower in spring than in the previous autumn (Fig. 1), it was not possible to formally compare these densities as different sites were sampled in the two seasons.

Holopneustes purpurascens on Ecklonia radiata were on average much larger than those on Delisea pulchra (Table 1, Fig. 2). Small urchins (0-20 mm diameter) were extremely rare on $E$. radiata, comprising only $1 \%$ of urchins from this host (Fig. 2). Conversely, large urchins ( $>40 \mathrm{~mm}$ diameter) were scarce on D. pulchra, comprising only $5.1 \%$ of urchins on this alga (Fig. 2). Temporal changes in size distribution were strongly dependent on habitat. Urchins on E. radiata did not change in size between sampling times (Table 1), but urchins on D. pulchra were significantly larger in spring (mean size: $24.23 \pm 0.96 \mathrm{~mm}$ ) than in autumn (mean size: $15.22 \pm 0.48 \mathrm{~mm}$; Table 1 ).

The abundance and size distribution of Holopneustes purpurascens in Ecklonia radiata forests was strongly related to the proximity of Delisea pulchra beds, with
TABle 1. Two-way ANOVA for size distributions of Holopneustes purpurascens between habitats and across sampling times at Bare Island, Australia.

\begin{tabular}{lrrrr}
\hline \hline \multicolumn{1}{c}{ Source } & \multicolumn{1}{c}{ df } & \multicolumn{1}{c}{ MS } & \multicolumn{1}{c}{$F$} & \multicolumn{1}{c}{$P$} \\
\hline Time & 1 & 2401.9 & 28.45 & $0.000^{* * *}$ \\
Habitat & 1 & 90344.9 & 1069.97 & $0.000^{* * *}$ \\
Time $\times$ habitat & 1 & 2818.2 & 33.38 & $0.000^{* * *}$ \\
Residual & 544 & 84.4 & & \\
\hline
\end{tabular}

Notes: Data are untransformed. Number of urchins: Ecklonia radiata, autumn, $n=178$; Delisea pulchra, autumn, $n$ $=164 ;$ E. radiata, spring, $n=98 ; D$. pulchra, spring, $n=$ 108. The results of a Tukey's hsd test on means within the season $\times$ habitat interaction showed that $D$. pulchra in autumn and spring were significantly different and $E$. radiata in spring and autumn were not significantly different at $P=0.05$. *** $P<0.001$.

more urchins in kelp forests bordered by D. pulchra than in isolated forests (one-factor ANOVA, $F_{1,118}=$ 34.67, $P<0.001$, with forests pooled $\left[F_{10,108}=0.382\right.$, $P>0.5]$; bordered forest mean density, $1.67 \pm 0.26$

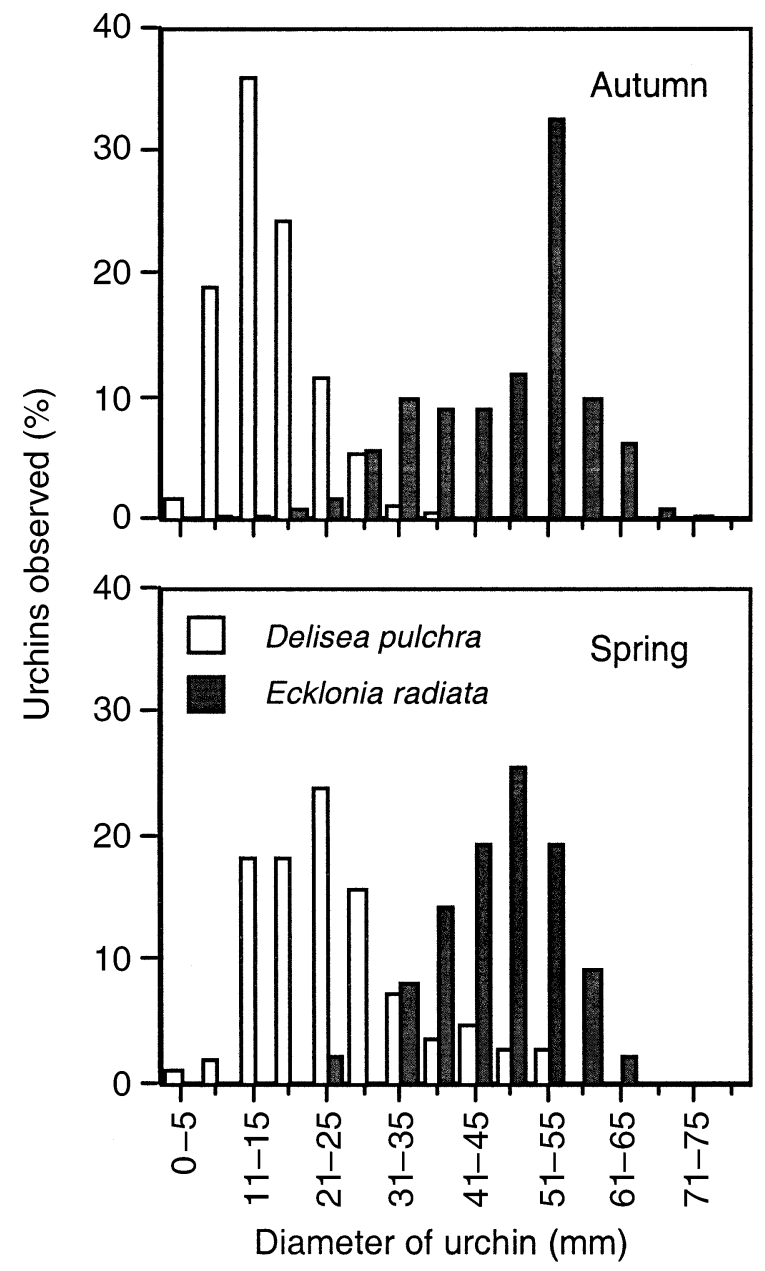

FIG. 2. Size distributions of Holopneustes purpurascens inhabiting Ecklonia radiata forests and Delisea pulchra beds at Bare Island at two sampling times. 


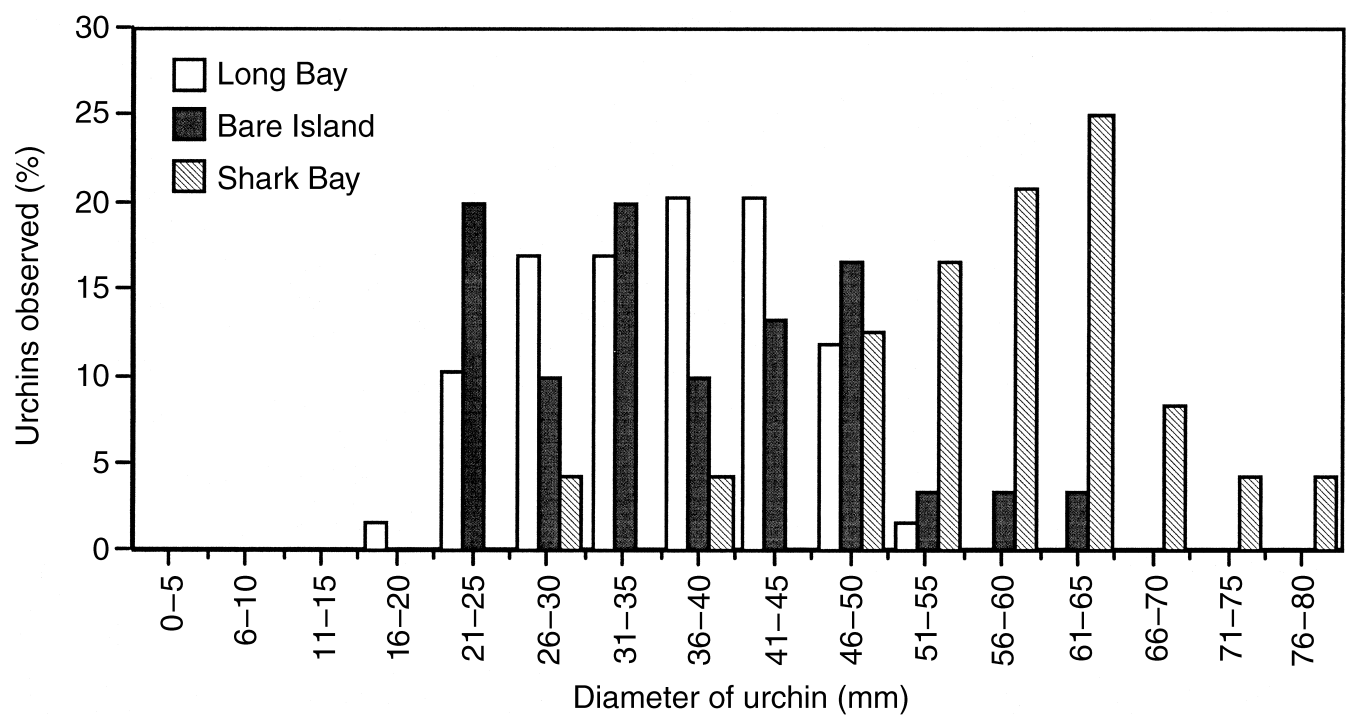

FIG. 3. Size distributions of Holopneustes purpurascens inhabiting Ecklonia radiata at Long Bay $(n=59)$, Bare Island $(n=30)$, and Shark Bay $(n=24)$.

urchins $/ 0.25 \mathrm{~m}^{2}$; isolated forest mean density, $0.42 \pm$ 0.11 urchins $/ 0.25 \mathrm{~m}^{2}$ ). The average size of urchins in isolated forests $(57.93 \pm 0.79 \mathrm{~mm})$ was significantly greater than in forests bordered by D. pulchra $(42.93$ $\pm 1.01 \mathrm{~mm}$; one-factor ANOVA, $F_{1,146}=120.80$,

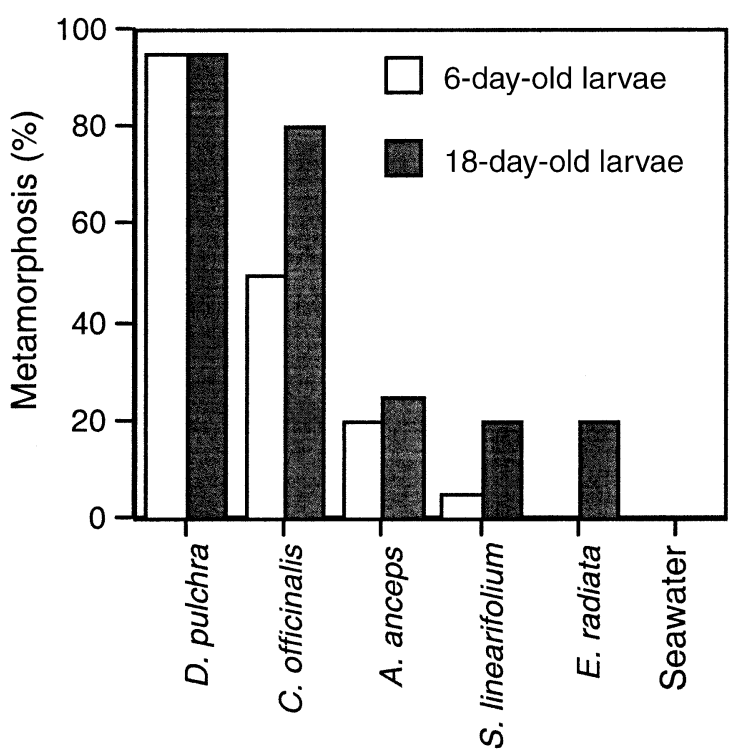

Algal species

FIG. 4. Percentage metamorphosis of competent Holopneustes purpurascens after $24 \mathrm{~h}$, using larvae that were either six days old or 18 days old (one larva/replicate, 20 replicates/ treatment) when exposed to subtidal algae (15 mg/replicate) from Bare Island. Treatments included three species of red algae (Delisea pulchra, Corallina officinalis, and Amphiroa anceps) and two species of brown algae (Sargassum linearifolium and Ecklonia radiata). The response of larvae to sterile filtered seawater was used as a control.
$P<0.001$; forests pooled $\left.\left[F_{4,142}=0.991, P>0.25\right]\right)$. No urchins $40 \mathrm{~mm}$ or smaller were observed in isolated forests.

When host plant use was assessed more broadly around Sydney, Holopneustes purpurascens were only found on Ecklonia radiata at Shark Bay, Little Bay, and Bare Island. Other algae surveyed at these sites were: the brown algae (Sargassum vestitum, S. linearifolium, Homeostrichus olsenii, Dictyota dichotoma, Padina crassa, Dilophus marginatus, Zonaria angustata, and Dictyopteris acrostichoides); the green algae (Caulerpa filiformis and Codium fragile); and the red algae (Champia viridis, Corallina officinalis, Amphiroa anceps, Laurencia obtuse, Delisea pulchra, and crustose coralline algae). Since there was no difference in the abundance of $E$. radiata plants between the three sites (one-factor ANOVA, $F_{2,92}=1.957, P=0.147$ ), the abundance of urchins per $E$. radiata plant was compared. There were significantly more urchins per plant at Shark Bay than Little Bay, but no differences in abundances between Bare Island and the other two sites (one-factor ANOVA, $F_{2,65}=3.439, P=0.038$ ). Urchins from Shark Bay were also significantly larger than those from the other two sites (one-factor ANOVA, $F_{2,110}=46.293, P<0.001$; Fig. 3). No H. purpurascens $<15 \mathrm{~mm}$ were found on $E$. radiata at any of these sites, and no urchins were found at Cape Banks at the time of sampling, although they were formerly abundant at this site (Steinberg 1995).

\section{Larval response to host plants}

Ninety-five percent of both six-day and 18-day-old larvae metamorphosed in response to Delisea pulchra (Fig. 4). At six days postfertilization, half the larvae metamorphosed to Corallina officinalis, a small pro- 


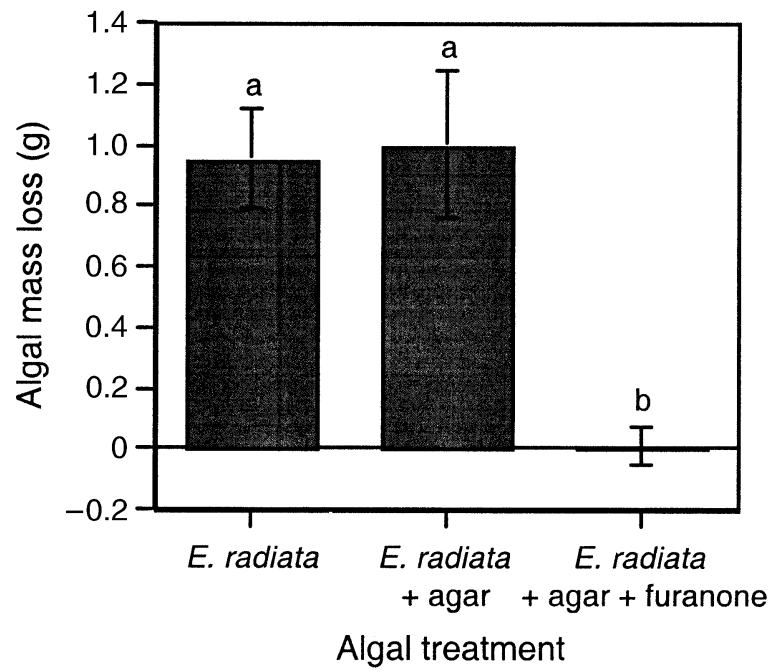

FIG. 5. Feeding rates (mean \pm 1 SE after 24 hours) of adult Holopneustes purpurascens on Ecklonia radiata coated with furanone 3 from Delisea pulchra $(n=15)$. Losses in mass (consumption) have been adjusted for autogenic loss in treatments lacking urchins. Bars labeled with the same letter do not differ significantly at $P=0.05$ (Tukey's hsd test).

portion to Amphiroa anceps, and one larva to Sargassum linearifolium. No metamorphosis of six-day-old larvae occurred in the presence of Ecklonia radiata or seawater. All algal treatments induced some metamorphosis in 18-day-old larvae, at levels equal to or greater than that observed for six-day-old larvae.

\section{Feeding rates of benthic urchins on different host plants}

The response of postmetamorphic Holopneustes purpurascens (juveniles or adults) to host plants contrasted strongly with the settlement preference of the larvae. H. purpurascens consumed significantly more Ecklonia radiata $(0.653 \pm 0.099 \mathrm{~g})$ than Delisea pulchra $(-0.094 \pm 0.046 \mathrm{~g})$ after 24 hours (one-factor ANOVA, $\left.F_{1,38}=26.524, P<0.001\right)$. Consumption of $D$. pulchra did not differ from zero.

Natural concentrations of the crude nonpolar extract from Delisea pulchra significantly inhibited feeding by Holopneustes purpurascens (one-factor ANOVA, $F_{2,42}$ $=18.227, P<0.001$; feeding rates for Ecklonia radiata $=0.607 \pm 0.106 \mathrm{~g}$, E. radiata plus agar $=0.712 \pm$ $0.092 \mathrm{~g}$, E. radiata plus agar and $D$. pulchra crude extract $=0.021 \pm 0.073 \mathrm{~g}$ ). Feeding by the urchins was completely inhibited by furanone 3 , the major secondary metabolite in $D$. pulchra (one-factor ANOVA, $F_{2,42}=9.650, P<0.001$; Fig. 5).

\section{Performance of benthic urchins on different host plants}

The long-term performance of Holopneustes purpurascens on Delisea pulchra was poor relative to performance on Ecklonia radiata. Growth of newly meta- morphosed $H$. purpurascens fed D. pulchra grew significantly less than those fed either E. radiata, Amphiroa anceps, or Corallina officinalis, and growth of those fed D. pulchra did not differ significantly from starved individuals (one-factor ANOVA, $F_{4,45}=$ 13.568, $P<0.001$; Fig. 6). Survival of these urchins was high and did not vary among treatments after three months $\left(\chi^{2}=3.804,4 \mathrm{df}, P=0.433\right)$. At the end of the experiment, no urchins fed $E$. radiata or $C$. officinalis had died, one urchin had died in each of the $A$. anceps and D. pulchra treatments, and two urchins had died in the starved treatments.

Long-term performance of mature urchins on different algal diets mirrored that of juvenile urchins. Mature Holopneustes purpurascens fed Delisea pulchra for three months did not grow, in contrast to the rapid growth of urchins fed Ecklonia radiata (one-factor ANOVA, $F_{2,45}=24.601, P<0.001$; Fig. 7a). Survival of urchins fed $E$. radiata was significantly greater than that of starved urchins after three months $\left(\chi^{2}=13.125\right.$, 2 df, $P=0.001$; Fig. 7b), but was only marginally greater than survival of urchins fed $D$. pulchra. Urchins fed Ecklonia radiata were also more fecund, with significantly greater gonad index (GI) values than those fed Delisea pulchra or starved (one-factor ANOVA, $F_{2,45}=60.183, P<0.001$; mean GI E. radiata, 3.535 \pm 0.342 ; mean GI D. pulchra, $0.599 \pm 0.158$; mean GI starved, $0.246 \pm 0.085$ ). GI values for urchins fed $E$. radiata were also similar (unpaired $t$ test (arcsine transformed), $t=0.862$, df $=31.9, P=0.395$; mean

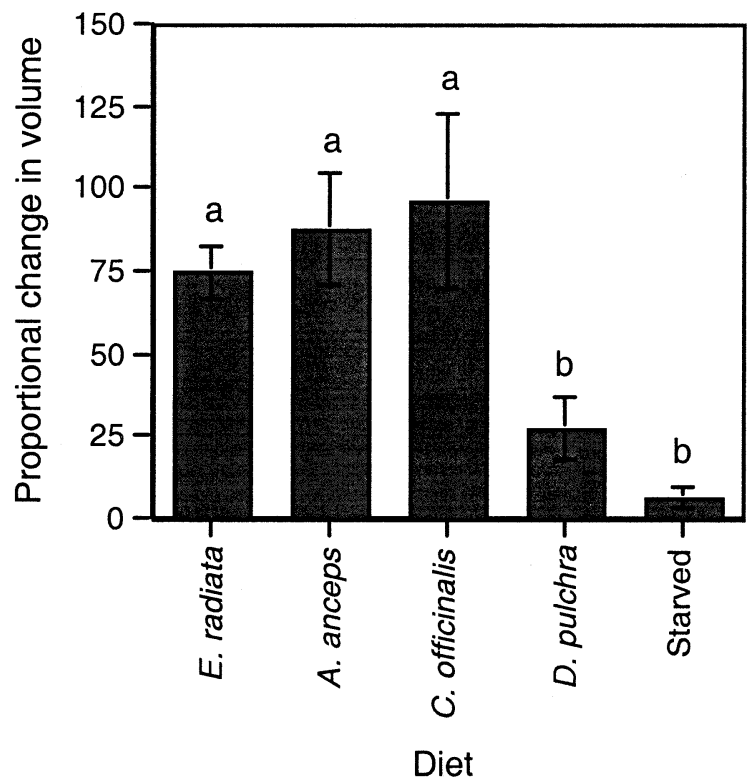

FIG. 6. Proportional change from initial volume (mean \pm $1 \mathrm{SE}$ ) for newly metamorphosed Holopneustes purpurascens fed ad libitum on diets of Ecklonia radiata, Amphiroa anceps, Corallina officinalis, or Delisea pulchra, or starved $(n=10$ urchins per treatment) after three months. Bars labeled with the same letter do not differ significantly at $P=0.05$ (Tukey's hsd test). 
a

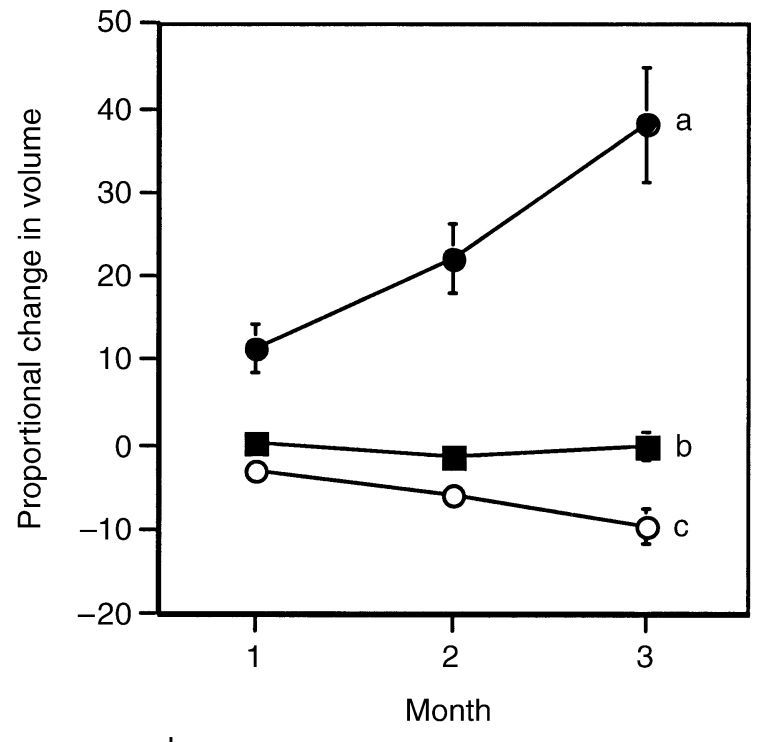

b

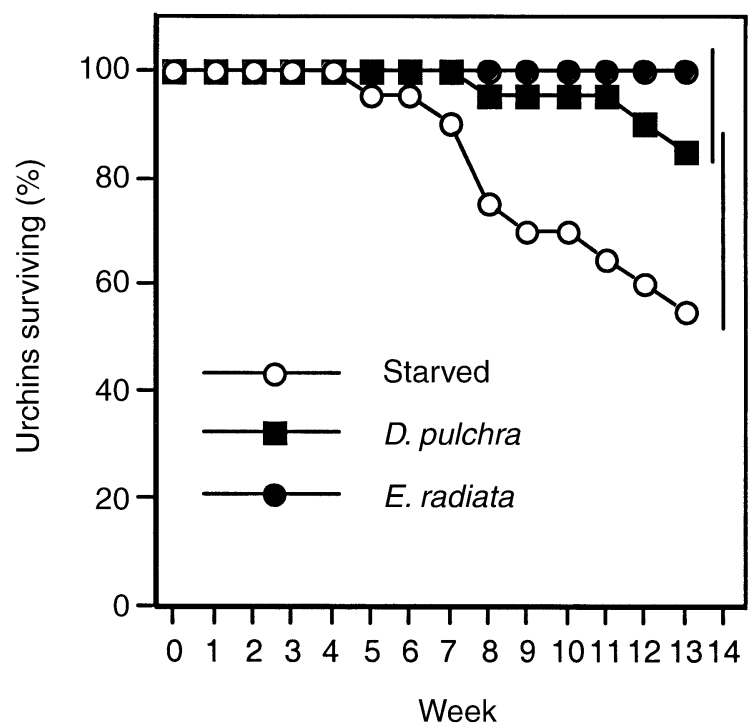

FIG. 7. (a) The proportional change from initial volume (mean $\pm 1 \mathrm{SE}$ ) of Holopneustes purpurascens fed ad libitum either Ecklonia radiata or Delisea pulchra, or starved $(n=$ 20 urchins per treatment) over three months. Treatments labeled with the same letter do not differ significantly at $P=$ 0.05 (Tukey's hsd test) after three months. (b) The percentage survivorship of Holopneustes purpurascens when fed ad libitum either Ecklonia radiata or Delisea pulchra, or starved $(n=20$ urchins per treatment). Treatments sharing a vertical line (at the right side of the figure) do not differ significantly at $P=0.01$ ( $G$ test) after three months.

GI field: $3.493 \pm 0.443)$ to those of field animals collected one year prior (Williamson and Steinberg 2002). Urchins fed $D$. pulchra had significantly smaller GI values than these field collected animals $(t=9.409$, df $=28.4, P<0.001)$. Moreover, gonads from urchins fed $E$. radiata could always be sexed at the end of the experiment, in contrast to $29 \%$ of the urchins fed $D$. pulchra and $0 \%$ (11 individuals) of urchins that were starved that could be sexed. Gonads from starved individuals contained empty lumens of the acini, indicating resorption in progress.

\section{Preferences and movement of urchins between host plants}

The benthic stage of Holopneustes purpurascens showed a strong preference for Ecklonia radiata in the laboratory and in the field. When offered a choice between Delisea pulchra and E. radiata in the laboratory, $87 \%$ of $H$. purpurascens moved on to laminae of $E$. radiata $\left(\chi^{2}=32.038,4 \mathrm{df}, P<0.000\right)$, while only $3 \%$ moved onto fronds of D. pulchra (10\% of urchins moved off both hosts, failing to exhibit a choice).

Results of reciprocal transplant experiments of algal thalli in the field were consistent with these laboratory preferences. Little movement of urchins occurred except when Ecklonia radiata laminae were transplanted into Delisea pulchra beds. Here, many urchins moved onto the kelp laminae from $D$. pulchra (two-factor ANOVA, $F_{2,138}=14.510, P<0.001$; Fig. 8). Numbers of urchins moving to transplants did not otherwise differ from controls (Fig. 8). This pattern was repeated when whole $E$. radiata plants were used. Significantly more urchins moved to whole kelp plants when they were transplanted into beds of D. pulchra when compared to habitat and transplant controls (one-factor ANOVA, $F_{2,62}=15.33, P<0.001$ ). Thus, laminae raised off the substratum (still attached to stipes) were no barrier to Holopneustes purpurascens attempting to move onto E. radiata.

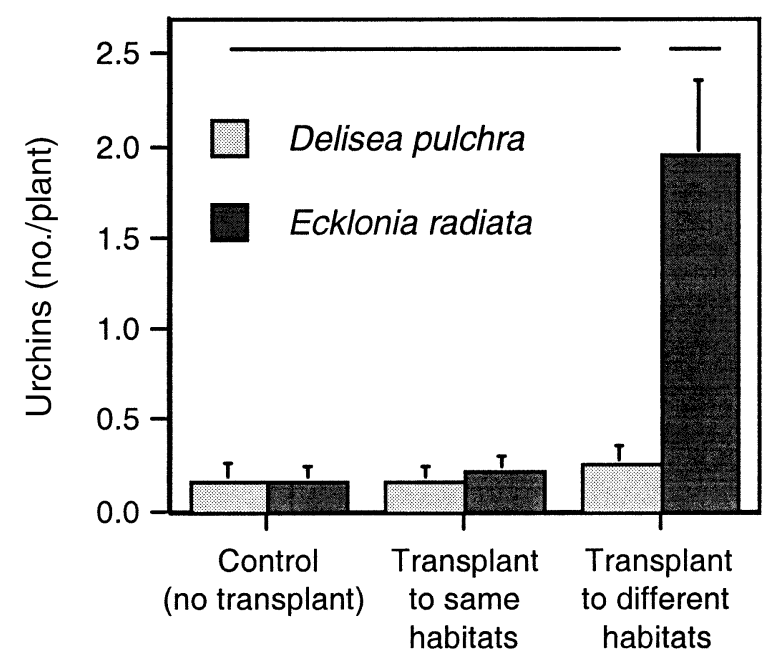

FIG. 8. Habitat preferences (mean +1 SE) of Holopneustes purpurascens moving onto transplanted Delisea pulchra and Ecklonia radiata laminae at night in the field $(n=$ 20). Treatments sharing a horizontal line (at the top of the figure) do not differ significantly at $P=0.05$ (Tukey's hsd test). 
TABLE 2. ANOVA comparing the number of bites taken from Holopneustes purpurascens by the damselfish Parma microlepis.

\begin{tabular}{lrrrc}
\hline \hline \multicolumn{1}{c}{ Source } & df & \multicolumn{1}{c}{ MS } & \multicolumn{1}{c}{$F$} & \multicolumn{1}{c}{$P$} \\
\hline Time & 3 & 11.33 & 47.32 & $0.000^{* * *}$ \\
Habitat & 2 & 0.27 & 1.15 & $>0.25 \mathrm{NS}$ \\
Cover & 1 & 11.72 & 48.96 & $0.000^{* * *}$ \\
Time $\times$ habitat & 6 & 0.25 & 1.04 & $>0.25 \mathrm{NS}$ \\
Time $\times$ cover & 3 & 4.19 & 17.50 & $0.000^{* * *}$ \\
Habitat $\times$ cover & 2 & 0.03 & 0.14 & $>0.5 \mathrm{NS}$ \\
Time $\times$ habitat $\times$ cover & 6 & 0.13 & 0.56 & $>0.5 \mathrm{NS}$ \\
Residual & 216 & 0.24 & & \\
\hline
\end{tabular}

Notes: Data were $\ln (x+1)$ transformed.

*** $P<0.001 ;$ NS, not significant $(P>0.05)$.

Assessment of movement of urchins off their host plants indicated that Holopneustes purpurascens were only found on the substratum (or on the subcanopy coralline turf) in Delisea pulchra habitats at night. There were $14.77 \%$ of urchins in D. pulchra beds found exposed on coralline turf at night, and all urchins found in Ecklonia radiata forests were enmeshed within the laminae of Ecklonia radiata at all times.

\section{Predation of urchins on host plants}

Bite rates by Parma microlepis on Holopneustes purpurascens over two minutes were significantly greater on exposed urchins during the day than on covered urchins during the day or covered or exposed urchins at night (Table 2, Fig. 9). No bites were observed at night. Consistent with the avoidance of a diurnally feeding predator, Holopneustes purpurascens showed significant diel trends in the use of both host plants as shelter. Most urchins were largely covered by their host plant during the day but less than one-quarter of all urchins were similarly sheltered at night (Fig. 10).

Underwater observations of large Holopneustes purpurascens exposed in beds of Delisea pulchra showed

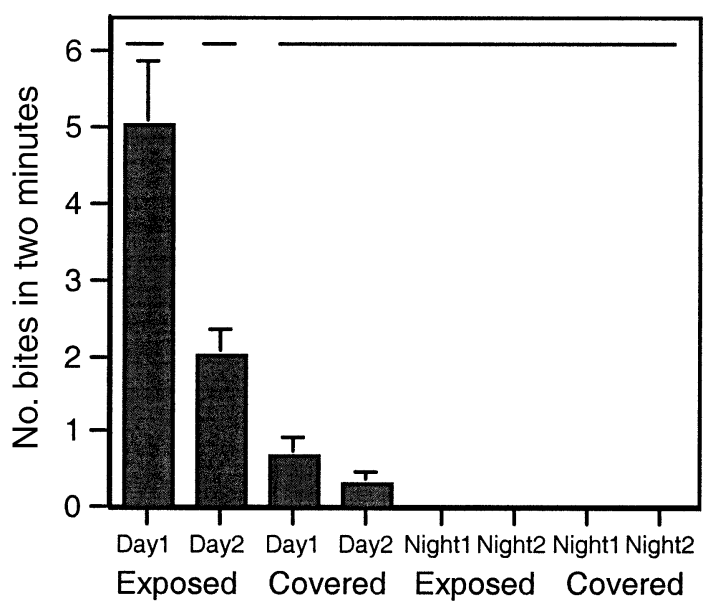

FIG. 9. Number (mean $+1 \mathrm{SE}$ ) of bites by Parma microlepis on Holopneustes purpurascens that were exposed vs. covered by algae ( $n=240,10$ replicates per treatment). Treatments sharing a horizontal line (at the top of the figure) do not differ significantly at $P=0.05$ (Tukey's hsd test). that an average feeding event by Parma microlepis removed $\sim 15 \%(14.75 \pm 3.75 \%$ over all times $)$ of an urchin's spines and tube feet, and that this was constant over the three sampling times (one-factor ANOVA, $\left.F_{2,12}=1.726, P=0.121\right)$. This level of spine and tube feet removal in the laboratory resulted in very high mortality of urchins (Table 3, Fig. 11). All but one of the urchins in the $10 \%$ removal treatment died after eight days (Fig. 11). All urchins with $50 \%$ of their spines and tube feet removed died within three days. In contrast, only one urchin died in the control over the 14 days (Fig. 11).

\section{DISCUSSION}

Most species of herbivores have complex life histories where the biology and natural history of different stages of the life cycle differ (Werner 1988, Bernays and Chapman 1994). Selection by such herbivores of appropriate host plants, or of habitats where these plants occur, is challenged by the fact that the dispersal phase of the life history (e.g., ovipositing butterfly or planktonic larvae) that is broadly responsible for

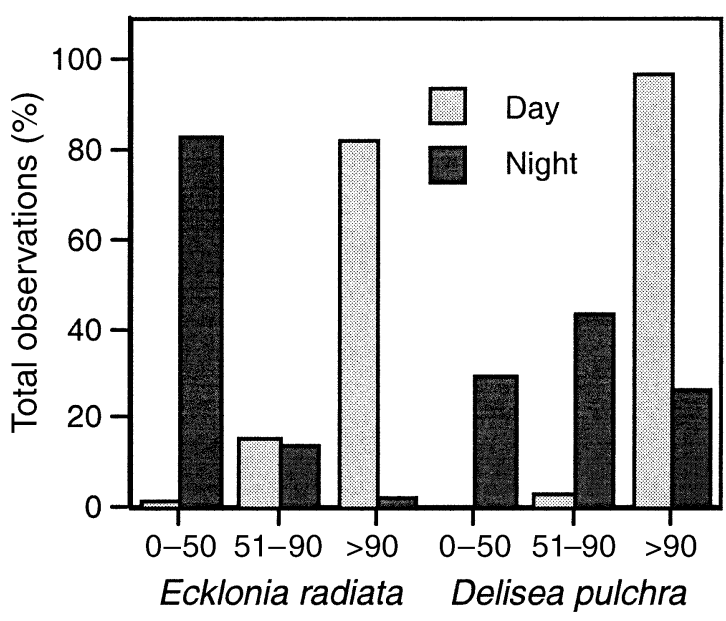

Amount of urchin covered by algae (\%)

FIG. 10. Diel patterns in the sheltering behavior of $\mathrm{Hol}$ opneustes purpurascens in Ecklonia radiata and Delisea pulchra $(n=0-152$ urchins per treatment). 
TABLE 3. Two-factor nested ANOVA comparing the mean days until death for Holopneustes purpurascens between a $50 \%$ loss of spines and tube feet, a $10 \%$ loss, and a $0 \%$ control ( $n=63$ urchins, 21 replicates per treatment).

\begin{tabular}{lrrrr}
\hline \hline \multicolumn{1}{c}{ Source } & df & \multicolumn{1}{c}{ MS } & \multicolumn{1}{c}{$F$} & \multicolumn{1}{c}{$P$} \\
\hline Loss (\%) & 2 & 696.89 & 913.36 & $0.000 * * *$ \\
Tank (\% loss) & 6 & 0.24 & 0.31 & $>0.05$ Ns \\
Residual & 52 & 0.76 & & \\
\hline
\end{tabular}

Notes: The results of a Tukey's hsd means test on percentage loss showed that times until death for a $0 \%$ control, $10 \%$ loss, and $50 \%$ loss were not significantly different at $P=0.05$.

*** $P<0.001 ;$ NS, not significant $(P>0.05)$.

choosing a habitat or a host plant is often not the phase that utilizes the host plant or habitat. For the many herbivores that use chemical cues to select and utilize host plants, this means there is the potential for chemical signals produced by plants to act differently or independently against different life history phases. For the Australian echinoid Holopneustes purpurascens, host plant chemicals and the response of different life history stages to them appear to be a major factor in the ecology of this species. Below we first discuss the demography of $H$. purpurascens with respect to chemical cues from its host algae, and then consider the broader implications for understanding host plant selection by marine herbivores.

\section{Demography and natural history of Holopneustes purpurascens}

Holopneustes purpurascens in this study showed a strong preference for two species of chemically rich host plants, the red alga Delisea pulchra and the kelp Ecklonia radiata. Abundances of $H$. purpurascens at Bare Island, our main study site, were similar on these two algae, but the size distribution of urchins on the two hosts differed substantially. H. purpurascens inhabiting $D$. pulchra were significantly smaller than those on $E$. radiata, and no urchins in the smallest size class (0-5 mm, reflecting new or recent recruits) were found on $E$. radiata. This difference was exacerbated for urchins in $E$. radiata forests that were isolated from beds of $D$. pulchra. $H$. purpurascens were less abundant in isolated forests and had a greater mean size than those on plants in forests that were bordered by D. pulchra beds. Moreover, the minimum size of urchins on kelp in isolated forests was twice that of those on plants in bordered forests.

These size distributions suggest that Holopneustes purpurascens recruits initially to Delisea pulchra, with postrecruitment colonization of Ecklonia radiata forests primarily occurring later (at larger sizes). H. purpurascens have a defined reproductive period, but are also capable of reproducing sporadically throughout the year (Williamson and Steinberg 2002). Colonization of isolated forests occurs less frequently than those bordered by $D$. pulchra. Consistent with this explanation, and with the presence of small urchins on $D$. pulchra only, competent larvae (six days postfertilization) of $H$. purpurascens metamorphosed rapidly in response to the host alga $D$. pulchra, and to a lesser degree to other benthic red algae (Fig. 5; Williamson et al. 2000). This response is due to a water-soluble cue released from $D$. pulchra (Fig. 5; Williamson et al. 2000) that rapidly induces metamorphosis in this urchin. Neither the polar nor the nonpolar extracts from $E$. radiata, nor water taken nearby this kelp in situ, induces metamorphosis in competent seven-day-old larvae (Williamson et al. 2000).

In the absence of an appropriate cue, however, larval Holopneustes purpurascens can delay metamorphosis and maintain competence for some time. Larvae maintained for 18 days postfertilization did metamorphose in response to Ecklonia radiata. The ability of larvae to be flexible in the duration of competency is well known for marine invertebrates that rely on specific cues for recruitment, with competent larvae becoming either less discriminating over time or experiencing a shift in the relative importance of potential cues (see Pechenik 1999 for review). For H. purpurascens, one consequence of such a decrease in discrimination over time may be an increased acceptance of E. radiata as a suitable host. Thus as the time spent in the water column is prolonged, a small proportion of larvae may metamorphose onto brown algae (e.g., E. radiata) as well as onto Delisea pulchra and other red algae. This occasional metamorphosis in response to $E$. radiata may explain the presence of urchins in isolated forests (urchins may also be carried there by water movement or on dislodged plants during storms).

Although larvae of Holopneustes purpurascens respond strongly to the polar cue from Delisea pulchra, and all urchins in the smallest size class occurred on D. pulchra, we found few actual new recruits (urchins 1-2 $\mathrm{mm}$ in diameter) on this or any other alga or sub-

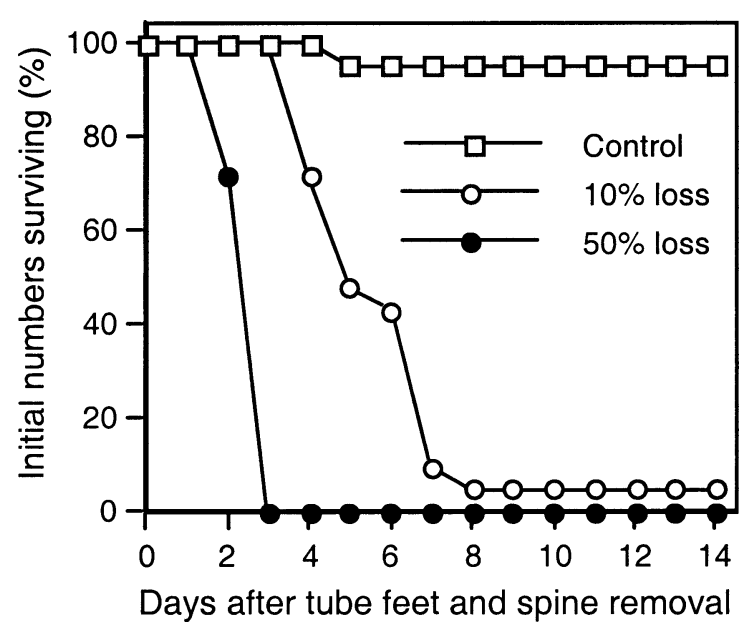

FIG. 11. Survival of Holopneustes purpurascens after the removal of different amounts of tube feet and spines $(n=21$ urchins per treatment). 
strata (Figs. 2 and 3; Williamson 2001). This may be for a number of reasons. Urchins $<2 \mathrm{~mm}$ may simply be very hard to sample. Alternatively, the low density of recruits (small urchins) at Bare Island and the lack of recruits at other sites around Sydney may indicate that recruitment of $H$. purpurascens is highly sporadic, like many other urchins (e.g., Rowley 1989).

An alternative explanation for the lack of recruits on Ecklonia radiata is that there is differential postrecruitment mortality of urchins inhabiting the two host plants. Although mortality of newly recruited individuals is crucial in determining patterns of distribution and abundance of adult populations for many marine invertebrates (Hunt and Scheibling 1997), we suggest that it is not the driving force behind the demography of Holopneustes purpurascens. The absence of any small urchins on E. radiata and the fact that larvae only metamorphosed in response to E. radiata after 18 days (and then only at low levels) suggests that recruitment onto this kelp is very low. Predation was minimal, and comparable, for urchins enmeshed in either E. radiata or Delisea pulchra (Fig. 9), although predation on new recruits was not studied. Abiotic factors, such as water motion, may potentially cause differential mortality, although we would predict that the effects of water motion would be greater for urchins inhabiting the relatively delicate $D$. pulchra than for the more robust $E$. radiata.

Surprisingly, once larvae settle and metamorphose on Delisea pulchra the resulting juveniles and adults do badly by all measures of performance used here, relative to performance on Ecklonia radiata. Although Holopneustes purpurascens readily ate E. radiata, they barely consumed the alga $D$. pulchra, preferred as a settlement substrate by the larval stage. This effect of D. pulchra on the benthic form can again be explained by metabolites from this host plant, but in this instance nonpolar secondary metabolites (furanones). Both the crude nonpolar extract from $D$. pulchra and the major secondary metabolite, (1'R,5Z)-3-(1'-acetoxybutyl)-4bromo-5-(bromomethylene) furan-2 $(5 H)$-one, or furanone 3 , strongly deterred feeding by this echinoid. $D$. pulchra is also a low preference food for the Australasian echinoids Tripneustes gratilla and Centrostephanus rodgersii, the gastropod Turbo undulata (Steinberg and van Altena 1992), and a broad range of generalist herbivores (Wright 2001). Although E. radiata is also rich in secondary metabolites, in particular polyphenolics, or phlorotannins (Steinberg and van Altena 1992), consumption of $E$. radiata by $H$. purpurascens is not affected by variation in these secondary metabolites (Steinberg 1995). Tolerance to brown algal phlorotannins in temperate Australasian echinoids is common (Steinberg and van Altena 1992, Steinberg et al. 1995).

Given the lack of consumption of Delisea pulchra by Holopneustes purpurascens, it was not surprising that the longer term performance by the urchin on this alga was also poor. For the first three months of benthic existence, growth of $H$. purpurascens on Ecklonia radiata and turfing red algae was significantly greater than for those fed D. pulchra, who grew at the same rate as starved individuals. Growth by starved individuals and those fed D. pulchra may have been due to the urchins utilizing residual nutrient reserves from their lecithotrophic larval stage, a common phenomenon in nonfeeding echinoid larvae (Emlet and HoeghGuldberg 1997). The growth of these juvenile urchins on the two red calcareous algae Amphiroa anceps and Corallina officinalis is also interesting, since the urchins were not commonly found on these species (Williamson 2001). However, coralline algae are common nursery grounds for many species of sea urchins (López et al. 1998) or other herbivores (Morse and Morse 1984), who appear to survive by grazing on a mixture of mucous exudates from the alga and diatoms, bacteria, and epiphytes growing on the alga's surface. The growth rate of larger urchins $(>10 \mathrm{~mm})$, however, is often low or negligible on coralline algae (Meidel and Scheibling 1999). Somatic growth of adult $H$. purpurascens only occurred when fed $E$. radiata. No adults fed $D$. pulchra grew and those that were starved actually decreased in size, as has been observed for other echinoids that display phenotypic plasticity in response to poor diets (Ebert 1967).

Holopneustes purpurascens fed Ecklonia radiata were also more fecund than those fed Delisea pulchra. Urchins fed $E$. radiata had significantly larger gonad index (GI) values than those fed D. pulchra, and there was no difference between GI values for $H$. purpurascens fed E. radiata and urchins collected from this kelp in the field in a previous study (Williamson and Steinberg 2002). The inability to sex all urchins that were starved and many that were fed $D$. pulchra, along with their smaller GI values, suggests that these urchins were resorbing nutrients from the gonads, as has been observed for other size classes of $H$. purpurascens ( $\mathrm{J}$. E. Williamson and P. D. Steinberg, unpublished manuscript) as well as other echinoids (e.g., Guillou and Michel 1993).

Consistent with the effects of diet on growth and reproduction, there was a trend for higher survival of Holopneustes purpurascens when fed Ecklonia radiata than when fed Delisea pulchra. This effect on survival is further supported by evidence presented elsewhere that the host plant the urchin originated from affects mortality of $H$. purpurascens. Urchins collected from D. pulchra exhibited poorer survival than urchins collected from $E$. radiata, even when raised on the same diet (J. E. Williamson and P. D. Steinberg, unpublished manuscript). This suggests that $D$. pulchra may have long lasting effects on $H$. purpurascens, even when the urchins are switched to a better diet.

The poor performance of urchins on algae on which they initially settle and metamorphose suggests that, following metamorphosis, Holopneustes purpurascens 
should move from Delisea pulchra onto the preferred host, Ecklonia radiata. Urchins in E. radiata forests were never observed on the substratum and appeared to only move up and down individual plants whereas those in D. pulchra beds were observed between the plants at night. Habitat preferences both in the field and the laboratory supported directional movement of $H$. purpurascens from $D$. pulchra to $E$. radiata. These results are again consistent with the differential size distributions on the two host algae.

Host plant chemistry, complex life histories, and models for host plant use by herbivores

Larvae of Holopneustes purpurascens metamorphose rapidly in response to a polar cue emanating from one of its two main hosts, the red alga Delisea pulchra, and the smallest size classes of this urchin were only found on this host plant. Recruits were difficult to find in the field and therefore differential mortality of newly recruited individuals on different host plants cannot be entirely ruled out as an explanation for this size distribution. However, the larval metamorphosis data and the demographic data strongly suggest that recruitment of $H$. purpurascens occurs primarily on D. pulchra. Once recruited, juveniles find themselves on a host unsuitable as food by the benthic phase, thereby pressuring the urchins to move off $D$. pulchra to seek appropriate food plants. We suggest that this results in increased movement of urchins in beds of D. pulchra relative to forests of $E$. radiata, and in a net directional movement of urchins from $D$. pulchra to $E$. radiata. Thus the planktonic (dispersal) phase of these urchins recruit preferentially onto a host that is an inappropriate choice for the benthic phase, and then appear to move to an alternative host that will support survival, growth, and reproduction.

The relationship between the preference of an organism recruiting onto a host plant and its subsequent performance on that host has been an important theme in the evolutionary ecology of plants and their herbivores (Thompson 1995). By far the most widely studied examples of host preference and performance studies are of oviposition preferences of adult phytophagous insects and subsequent performance of their offspring on host plants (Futuyma and Moreno 1988, Bernays and Chapman 1994, Mayhew 2001). Many insect herbivores are selective feeders, with relatively sedentary larvae that are constrained to feeding on the host plants on which their mother deposited eggs (Mayhew 2001). For such animals, preference is exhibited by the dispersive adult, and performance a function of the growth and survival of the larvae.

Correlations between adult preference and offspring performance for insects range from strong (e.g., Rausher 1982, Craig et al. 1989) to poor (e.g., Courtney and Kibota 1990, Rank et al. 1998), indicating that adult females do not always choose host plants that give optimal performance for their progeny (Mayhew 2001).
Analogous information on preference-performance relationships for marine herbivores is rare, although some marine larvae (not herbivores) have been shown to recruit to unfavorable habitats (e.g., Strathmann et al. 1981). In general, marine studies have either concentrated on a particular stage within a herbivore's life history (e.g., feeding deterrence vs. growth in the benthic stage; Steinberg and Van Altena 1992, Pennings and Paul 1993), or have been done on herbivores that lack complex life histories. Prime examples of the latter include amphipods and isopods that have short generation times and release brooded juveniles onto their host plants (e.g., Duffy and Hay 1991, Poore and Steinberg 1999, Cruz-Rivera and Hay 2001). Of these studies, relationships between preference of a host plant and subsequent performance on that host have also ranged from strong to weak. For example, Poore and Steinberg (1999) found a positive relationship between adult host choice and subsequent performance of larvae for the tube building amphipod Peramphithoe parmerong. Duffy and Hay (1991, 1994), however, found no consistent relationship between host plant use and preference for survival and reproduction of the amphipod Ampithoe longimana. Similarly, the isopod Idotea baltica readily chooses and feeds on phenolic-rich host plants that carry the cost of a decreased rate of growth, presumably due to predation avoidance (Jormalainen et al. 2001).

For marine herbivores with complex life histories, however, little is known regarding preference/performance relationships of the larval and benthic phases, and almost nothing is known about the ways that host plant chemistry mediates this relationship. Of the few studies that have addressed this issue, most show a mismatch between larval settlement preference and benthic preference. For example, larvae of Aplysia californica recruit onto algae that are not a preferred food for the benthic stage (Pawlik 1989). A. californica metamorphosed in response to a wide range of algae, particularly reds, then moved to their preferred source of food immediately following metamorphosis. Similarly, while many species of abalone preferentially recruit onto crustose coralline algae (Morse and Morse 1984, Morse 1990), performance for adults is best when consuming foliose macroalgae (Shepherd and Daume 1996).

Thompson (1995) has identified a number of reasons as to why there may not be a strong relationship between host preference and performance for herbivores in general. In particular, herbivores may select host plants on which they perform poorly in terms of growth or consumption if they gain other advantages such as increased protection from predation. There are examples of this in both terrestrial (Price et al. 1980, Bernays 1989) and marine (Hay et al. 1987, Hay and Steinberg 1992) systems, and this explanation has been extensively developed to explain patterns of host use for marine "mesograzers." Mesograzers (Brawley 1992) 
use algae as habitat and food, and are often relatively tolerant to algal secondary metabolites that deter feeding of larger herbivores (reviewed in Hay 1996). Duffy and Hay (1991) argued that preference by mesograzers for algae that contained high levels of noxious compounds and supported suboptimal performance, has evolved as a way for many mesograzers to avoid being consumed by larger herbivores or omnivores that are often deterred by these algal secondary compounds. Thus many such species select algal hosts on the basis of their quality as a habitat, rather than food (Arrontes 1999).

Holopneustes purpurascens is larger as an adult than most mesograzers, but otherwise fits the criteria of using host plants as both food and habitat during part of its life history. As with many other urchins (Andrew 1993, Scheibling 1996), predation from visually hunting fishes appears to be an important factor in the ecology of this urchin. Decreased predation associated with living on a chemically well-defended host has been proposed as a major selective factor for host plant use by mesograzers (Duffy and Hay 1991, 1994). Thus the demography of $H$. purpurascens on its two hosts may be caused by differential attacks on urchins inhabiting the two host plants as a result of differing plant chemistry, with Delisea pulchra providing extra shelter from predators.

However, we view this hypothesis as unlikely for $H$. purpurascens. When exposed (outside of a host alga) during the day, $H$. purpurascens are rapidly attacked by the damselfish Parma microlepis, suffering significant losses $(\sim 15 \%)$ of tube feet and spines. Furthermore, a laboratory experiment that showed only a $10 \%$ removal of tube feet and spines in $H$. purpurascens resulted in $95 \%$ mortality in six days, suggesting that $P$. microlepis (and probably other fishes) can be a considerable threat to these urchins. However, H. purpurascens exhibit a diurnal sheltering behavior, remaining cryptically wrapped in their host plants during the day and are only exposed at night when predation is thought to be lower and $P$. microlepis are inactive (Rogers et al. 1998). While predation may be influential in maintaining the cryptic behavior of $H$. purpurascens in general, no predation was observed when urchins were camouflaged in either Delisea pulchra or Ecklonia radiata. Therefore differential predation on urchins on different host plants is unlikely as an explanation for host plant use in this echinoid.

We suggest that larval preference for Delisea pulchra is a "mistake." Other red algae besides D. pulchra induce metamorphosis of competent larvae of Holopneustes purpurascens, but at a lower rate (Williamson et al. 2000). However, since D. pulchra is by far the most abundant foliose red alga at Bare Island (Wright et al. 2000), higher concentrations of the cue for metamorphosis should surround beds of D. pulchra than in water surrounding other species of red algae. Therefore, $H$. purpurascens larvae may simply be responding to the highest local concentration of a more widespread chemical cue that in this habitat results in larvae metamorphosing on or nearby a host plant that is not consumed by the urchin. $H$. purpurascens then secondarily colonize E. radiata in the benthic phase. Such mistakes in host plant selection by the dispersal phase have been suggested for other terrestrial and marine organisms (Futuyma et al. 1984, Hay et al. 1987, Thompson 1995). For insects, however, these mistakes are usually made by the mother making a poor choice in host plant selection for her larvae, rather than a poor choice by the larval stage itself (Thompson 1995).

Ultimately, the consequence of larval choice by Holopneustes purpurascens is a demographic bottleneck that restricts survival, growth, and reproduction of the urchins until they can move to an alternative host. Such demographic bottlenecks are not uncommon for benthic marine species with complex life cycles and typically involve a shift in habitat use and/or diet relatively soon after metamorphosis. In general, the focus of such studies has been on a mediation of the shift by an interaction between the physical structure/nature of the habitat and the size of the organism. Thus shifts have been attributed to a range of abiotic factors such as temperature (e.g., Underwood 1979), desiccation (e.g., Menge 2000), the complexity of the habitat (e.g., Beck 1995), and dislodgement by the effects of waves (e.g., Faller-Fritsch and Emson 1986). More recently, biotic factors such as disease (e.g., Zann et al. 1987) and predation (e.g., Arsenault and Himmelman 1998) have also been shown to mediate ontogenetic shifts. This study is the first to suggest that such a shift can be brought about, in part, by a differential response to host plant metabolites between the larval and benthic stage of a marine herbivore. Complex life histories are widespread among marine herbivores, thus an integrated approach to the study of the effects of natural metabolites across all life history stages of such animals is likely to prove valuable for understanding their ecology and evolution.

\section{ACKNOWLEDGMENTS}

We thank Symon Dworjanyn, Alistair Poore, and Richard Taylor for comments on this manuscript. This research was supported by an Australian Postgraduate Award to J. E. Williamson, an ARC Research Fellowship to R. de Nys, ARC Large Grants to P. D. Steinberg and R. de Nys, and the Centre for Marine Biofouling and Bio-Innovation.

\section{Literature Cited}

Andrew, N. L. 1993. Spatial heterogeneity, sea urchin grazing, and habitat structure on reefs in temperate Australia. Ecology 74:292-302.

Arrontes, J. 1999. On the evolution of interactions between marine mesoherbivores and algae. Botanica Marina 42: 137-155.

Arsenault, D. J., and J. H. Himmelman. 1998. Size-related decrease in spatial refuge use by Iceland scallops Chlamys islandica: ontogenetic behavioural changes or decreasing refuge availability? Marine Ecology Progress Series 162: 153-161. 
Beck, M. W. 1995. Size-specific shelter limitation in stone crabs: a test of the demographic bottleneck hypothesis. Ecology 76:968-980.

Bernays, E. A. 1989. Host range in phytophagous insects: the potential role of generalist predators. Evolutionary Ecology 3:299-311.

Bernays, E. A., and R. F. Chapman. 1994. Host-plant selection by phytophagous insects. Chapman and Hall, New York, New York, USA.

Brawley, S. H. 1992. Mesoherbivores. Pages 235-263 in D. M. John, S. J. Hawkins, and J. H. Price, editors. Plantanimal interactions in the marine benthos. Clarendon Press, Oxford, UK.

Courtney, S. P., and T. T. Kibota. 1990. Mother doesn't know best: selection of hosts by ovipositing insects. Pages 161188 in E. A. Bernays, editor. Insect-plant interactions. Volume II. CRC Press, Boca Raton, Florida, USA.

Craig, T. P., J. K. Itami, and P. W. Price. 1989. A strong relationship between oviposition preference and larval performance in a shoot-galling sawfly. Ecology 70:1691-1699.

Cruz-Rivera, E., and M. E. Hay. 2001. Macroalgal traits and the feeding and fitness of an herbivorous amphipod: the roles of selectivity, mixing, and compensation. Marine Ecology Progress Series 218:249-266.

de Nys, R., J. C. Coll, and B. F. Bowden. 1992. Delisea pulchra (cf. fimbriata) revisited. The structural determination of two new metabolites from the red alga Delisea pulchra. Australian Journal of Chemistry 45:1625-1632.

de Nys, R., P. D. Steinberg, C. N. Rogers, T. S. Charlton, and M. N. Duncan. 1996. Quantitative variation of secondary metabolites in the sea hare Aplysia parvula and its host plant Delisea pulchra. Marine Biology 130:135-146.

de Nys, R., A. D. Wright, G. M. Konig, and O. Sticher. 1993. New halogenated furanones from the marine alga Delisea pulchra (cf. fimbriata). Tetrahedron 49:11213-11220.

Duffy, J. E., and M. E. Hay. 1991. Food and shelter as determinants of food choice by an herbivorous marine amphipod. Ecology 72:1286-1298.

Duffy, J. E., and M. E. Hay. 1994. Herbivore resistance to seaweed chemical defense: the roles of mobility and predation risk. Ecology 75:1304-1319.

Ebert, T. A. 1967. Negative growth and longevity in the purple sea urchin Strongylocentrotus purpuratus (Stimpson). Science 157:557-558.

Emlet, R. B., and O. Hoegh-Guldberg. 1997. Effects of egg size on postlarval performance: experimental evidence from a sea urchin. Evolution 51:141-152.

Faller-Fritsch, R. J., and R. H. Emson. 1986. Causes and patterns of mortality in Littorina rudis (Maton) in relation to interspecific variation: a review. Pages 157-177 in P. G. Moore and R. Seed, editors. The ecology of rocky coasts: essays presented to J. R. Lewis. Hodder and Stoughton, London, UK.

Futuyma, D. J., R. P. Cort, and I. V. Noordwijk. 1984. Adaptation to host plants in the fall cankerworm (Alsophila pometaria) and its bearing on the evolution of host affiliation in phytophagus insects. American Naturalist 123: 287-296.

Futuyma, D. J., and G. Moreno. 1988. The evolution of ecological specialization. Annual Review of Ecology and Systematics 19:207-233.

Guillou, M., and C. Michel. 1993. Reproduction and growth of Sphaerechinus granularis (Echinodermata: Echinoidea) in Southern Brittany. Journal of the Marine Biological Association of the United Kingdom 73:179-192.

Hay, M. E. 1996. Marine chemical ecology: what's known and what's next? Journal of Experimental Marine Biology and Ecology 200:103-134.

Hay, M. E., J. E. Duffy, C. A. Pfister, and W. Fenical. 1987. Chemical defence against marine herbivores: are amphipods insect equivalents? Ecology 68:1567-1580.
Hay, M. E., and P. D. Steinberg. 1992. The chemical ecology of plant-herbivore interactions in marine versus terrestrial communities. Pages 371-413 in G. A. Rosenthal and M. Berembaum, editors. Herbivores: their interaction with secondary plant metabolites. Volume II. Ecological and evolutionary processes. Academic Press, San Diego, California, USA.

Hentschel, B. T. 1999. Complex life cycles in a variable environment: predicting when the timing of metamorphosis shifts from resource dependent to developmentally fixed. American Naturalist 154:549-558.

Hunt, H. L., and R. E. Scheibling. 1997. Role of early postsettlement mortality in recruitment of benthic marine invertebrates. Marine Ecology Progress Series 155:269-301.

Jormalainen, V., T. Honkanen, and N. Heikkilä. 2001. Feeding preferences and performance of a marine isopod on seaweed hosts: cost of habitat specialization. Marine Ecology Progress Series 220:219-230.

López, S., X. Turon, E. Montero, C. Palacín, C. M. Duarte, and I. Tarjuelo. 1998. Larval abundance, recruitment and early mortality in Paracentrotus lividus (Echinoidea). Interannual variability and plankton-benthos coupling. Marine Ecology Progress Series 172:239-251.

Mayhew, P. J. 2001. Herbivore host choice and optimal bad motherhood. Trends in Ecology and Evolution 16:165-167.

Meidel, S. K., and R. E. Scheibling. 1999. Effects of food type and ration on reproductive maturation and growth of the sea urchin Strongylocentrotus droebachiensis. Marine Biology 134:155-166.

Menge, B. A. 2000. Recruitment vs. postrecruitment processes as determinants of barnacle population abundance. Ecological Monographs 70:265-288.

Morse, A. N. C., and D. E. Morse. 1984. Recruitment and metamorphosis of Haliotis larvae induced by molecules uniquely available at the surfaces of crustose red algae. Journal of Experimental Marine Biology and Ecology 75: 191-215.

Morse, D. E. 1990. Recent progress in larval settlement and metamorphosis: closing the gaps between molecular biology and ecology. Bulletin of Marine Science 46:465-483.

Paul, V. J., E. Cruz-Rivera, and R. W. Thacker. 2001. Chemical mediation of macroalgal-herbivore interactions: ecological and evolutionary perspectives. Pages 227-265 in J. B. McClintock and B. J. Baker, editors. Marine chemical ecology. CRC Press, Boca Raton, Florida, USA.

Pawlik, J. R. 1989. Larvae of the sea hare Aplysia californica settle and metamorphose on an assortment of macroalgal species. Marine Ecology Progress Series 51:195-199.

Pawlik, J. R. 1992. Chemical ecology of the settlement of benthic marine invertebrates. Oceanography and Marine Biology: an Annual Review 30:273-335.

Pechenik, J. A. 1999. On the advantages and disadvantages of larval stages in benthic marine invertebrate life cycles. Marine Ecology Progress Series 177:269-297.

Pennings, S. C., and V. J. Paul. 1993. Secondary chemistry does not limit dietary range of the specialist sea hare Stylocheilus longicauda (Quoy et Gainard 1824). Journal of Experimental Marine Biology and Ecology 174:97-113.

Peterson, C. H., and P. E. Renaud. 1989. Analysis of feeding preference experiments. Oecologia 80:82-86.

Poore, A. G. B., and P. D. Steinberg. 1999. Preference-performance relationships and effects of host plant choice in an herbivorous marine amphipod. Ecological Monographs 69:443-464.

Price, P. W., C. E. Bouton, P. Gross, B. A. McPherson, J. N. Thompson, and A. E. Weiss. 1980. Interactions among three trophic levels: influence of plants on interactions between herbivores and natural enemies. Annual Review of Ecology and Systematics 11:41-65. 
Ragan, M. A., and K.-W. Glombitza. 1986. Phlorotannins, brown algal polyphenols. Progress in Phycological Research 4:129-241.

Rank, N. E., A. Köpf, R. Julkunen-Tiitto, and J. Tahvanainen. 1998. Host preference and larval performance of the salicylate-using leaf beetle Phratora vitellinae. Ecology 79 : 618-631.

Rausher, M. D. 1982. Population differentiation in Euphydryas editha butterflies: larval adaptation to different hosts. Evolution 36:581-590.

Rogers, C. N., J. E. Williamson, D. G. Carson, and P. D. Steinberg. 1998. Diel vertical movement by mesograzers on seaweeds. Marine Ecology Progress Series 166:301306.

Rowley, R. J. 1989. Settlement and recruitment of sea urchins (Strongylocentrotus spp.) in a sea-urchin barren ground and a kelp bed: are populations regulated by settlement or postsettlement processes? Marine Biology 100:485-494.

Scheibling, R. E. 1996. The role of predation in regulating sea urchin populations in eastern Canada. Oceanologica Acta 19:421-430.

Shepherd, S. A., and S. Daume. 1996. Ecology and survival of juvenile abalone in a crustose coralline habitat in South Australia. Pages 297-313 in Y. Watanabe, Y. Yamashita and Y. Oozeki, editors. Proceedings of an international workshop, (Yokohama, Japan). Balkema Press, Rotterdam, The Netherlands.

Sokal, R. R., and F. J. Rohlf. 1995. Biometry. Third edition. W. H. Freeman, New York, New York, USA.

Steinberg, P. D. 1995. Interaction between the canopy dwelling echinoid Holopneustes purpurescens and its host kelp Ecklonia radiata. Marine Ecology Progress Series 127: 169-181.

Steinberg, P. D., J. A. Estes, and F. C. Winter. 1995. Evolutionary consequences of food chain length in kelp forest communities. Proceedings of the National Academy of Sciences (USA) 92:8145-8148.

Steinberg, P. D., and I. van Altena. 1992. Tolerance of marine invertebrate herbivores to brown algal phlorotannins in temperate Australasia. Ecological Monographs 62:189222.

Strathmann, R. R., E. S. Branscomb, and K. Vedder. 1981. Fatal errors in set as a cost of dispersal and the influence of intertidal flora on set of barnacles. Oecologia 48:13.
Thompson, J. N. 1995. The coevolutionary process. University of Chicago Press, Chicago, Illinois, USA.

Underwood, A. J. 1979. The ecology of intertidal gastropods. Advances in Marine Biology 16:111-210.

Underwood, A. J., M. J. Kingsford, and N. L. Andrew. 1991. Patterns in shallow subtidal marine assemblages along the coast of New South Wales. Australian Journal of Ecology 6:231-249.

Werner, E. E. 1988. Size, scaling and the evolution of complex life cycles. Pages 60-81 in B. Ebenman and L. Persson, editors. Size-structured populations. Springer, New York, New York, USA.

Williamson, J. E. 2001. Larval attractants versus adult deterrents: ontogenetic shifts in the response of a sea urchin to host plant chemistry. Dissertation. University of New South Wales, Sydney, Australia.

Williamson, J. E., R. de Nys, N. Kumar, D. G. Carson, and P. D. Steinberg. 2000. Induction of metamorphosis in the sea urchin Holopneustes purpurascens by a metabolite complex from the algal host Delisea pulchra. Biological Bulletin 198:332-345.

Williamson, J. E., and P. D. Steinberg. 2002. Reproductive cycle of the sea urchin Holopneustes purpurascens (Temnopleuridae: Echinodermata). Marine Biology 140:519532.

Winer, B. J., D. R. Brown, and K. M. Michels. 1991. Statistical principles in experimental design. McGraw-Hill, Sydney, Australia.

Wright, J. T. 2001. Population dynamics, genetic structure and evolution of chemical defences in a marine alga. Dissertation. University of New South Wales, Sydney, Australia.

Wright, J. T., R. de Nys, and P. D. Steinberg. 2000. Geographic variation in halogenated furanones from the red alga Delisea pulchra and associated herbivores and epiphytes. Marine Ecology Progress Series 207:227-241.

Zann, L., J. Brodie, C. Berryman, and M. Naqasima. 1987. Recruitment, ecology, growth and behavior of juvenile Acanthaster planci (L.) (Echinodermata: Asteroidea). Bulletin of Marine Science 41:561-575.

Zar, J. H. 1984. Biostatistical analysis. Prentice-Hall, Englewood Cliffs, New Jersey, USA. 